\title{
Inter-regional variability in site index models for even-aged stands of stone pine (Pinus pinea L.) in Spain
}

\author{
Rafael Calama $^{\mathrm{a} *}$, Nieves Cañadas ${ }^{\mathrm{b}}$ and Gregorio Montero ${ }^{\mathrm{a}}$ \\ ${ }^{a}$ Centro de Investigación Forestal, CIFOR-INIA, Apdo. 8111, 28080 Madrid, Spain \\ b Dirección General del Medio Natural, Consejería de Medio Ambiente, Comunidad de Madrid, Princesa, 3. Madrid, Spain
}

(Received 7 December 2001; accepted 3 June 2002)

\begin{abstract}
Data from 96 stem analysis and 37 permanent plots in even-aged stands of stone pine (Pinus pinea L.) in four regions of Spain (Central Range, Northern Plateau, West Andalusia and Catalonia) are used to develop a dominant height growth model for each region. These models are compared to detect similarities or differences in height growth patterns between regions, which will justify the need to build more regional site index curves for the species in Spain. Comparing these models involves homogeneity tests of parameters and a statistical analysis of the bias.
\end{abstract}

site index / model / inter-regional / height growth / Pinus pinea

Résumé - Variabilité inter-régionale des modèles de site index pour les peuplements réguliers de pin pignon (Pinus pinea L.) en Espagne. Les données de 96 analyses de tige et de 37 placettes permanentes de pin pignon (Pinus pinea L.) réparties dans quatre régions d'Espagne (Massif central, Plateau de Nord-Castille, Andalousie et Catalogne) ont été utilisées pour le développement d'un modèle de croissance (hauteur dominante) pour chaque région. Les modèles sont comparés entre eux afin de détecter des similarités ou des différences sur la croissance en hauteur entre les peuplements des quatre régions, ce qui pourrait justifier la nécessité de construire des modèles régionaux pour Pinus pinea en Espagne. Pour comparer les modèles entre eux, des tests sur l'homogénéité de paramètres et des analyses statistiques de biais ont été utilisés.

site index / modèle / inter-régional / croissance en hauteur / Pinus pinea

\section{INTRODUCTION}

There has recently been a large increase in the publication of new growth models and site index curves for different species. This increase has been accompanied by a decrease in the geographic range of validity for the application of these models, with the range being reduced more and more to smaller regions.

Variability detected between growth and site index models developed for the same species in different geographical and/ or ecological regions could be influenced by the existing differences in the methodology used for data collection and processing. In these cases, the administrative barrier between two different regions or countries could lead to significant differences between growth models that are not based on ecological or biological reasons [1].

Although the methodology used in different regions or countries could be similar, it is necessary to determine if there are significant differences between the dominant height growth patterns for a given species growing under different ecologic or geographic conditions. This will help us to decide whether new site index models are necessary or whether a fewer number of curves will allow us to represent and express the growth pattern for dominant height with the precision level required by forest managers $[1,11,12,20,31,32]$. Finally, it is also necessary to determine if the increase in the predictive level that we obtain when we are developing a model for a small geographic region justifies the cost we have invested in building it, or if it is more useful to apply a single model for wide areas. In this case, despite a small loss in the prediction ability of the model, we can make comparisons in potential productivity for different regions, giving forest managers the possibility of applying the same techniques in stands growing in different areas under similar site conditions [1].

Stone pine (Pinus pinea L.) is a typical Mediterranean forest species. In Spain it occupies more than 400000 ha, which is more than $50 \%$ of the total area occupied by the species in the world. Pinus pinea stands have an important ecological, landscape, recreation and soil conservation use. This importance, together with the economical yield of its two principal

* Correspondence and reprints

Tel.: (34) 9134768 68; fax: (34) 9135722 93; e-mail: rcalama@inia.es 


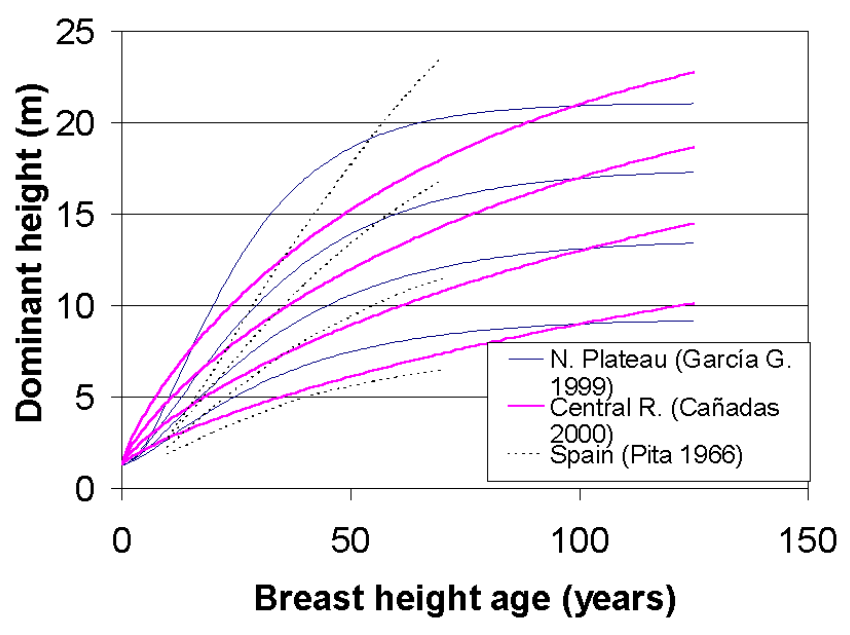

Figure 1. Site index curves for Pinus pinea L. published in Spain.

products, wood and pinyon nut, which have a relative high value in the rural environment where the species is found, have resulted in a large increase in the interest of the species for forest managers and researchers. As a result, several site index curves for Pinus pinea in Spain have been developed and published $[5,14,26]$. All these models, except the one developed by Pita [26], have a regional character, having been proposed and validated only for a given region in Spain.

Site index curves for Pinus pinea in Spain have been built using different methodologies, in data collection, chosen function, index age and statistical analysis. The graphical analysis of these curves (figure 1) also reflects the existence of different growth patterns among the regions.

The lack of homogeneity in data collection and in its analysis prevents us from determining if the differences detected among growth patterns are a consequence of interregional variability, or are caused by the absence of a single criterion to be used in data collection and analysis.

The aim of this work is to select a single function that will describe and predict the growth of dominant height for Pinus pinea in Spain. This function will be fitted to homogeneous data obtained in even-aged stands of Pinus pinea located in four different Spanish regions (figure 2): Northern Plateau (Meseta Norte), Central Range (Sistema Central), West Andalusia (Andalucía Occidental) and Catalonia (Cataluña). This will allow us to analyse the inter-regional variability in dominant height growth patterns for Pinus pinea stands, and to determine whether it is possible to reduce the number of site index curves and growth models. In the same way, if we detect the existence of significant differences among the regional models, we would determine and evaluate the degree of error committed by applying a combined model fitted for a group of regions, instead of applying separate models for each region.

\section{MATERIALS AND METHODS}

\subsection{Data set}

In this research, we have studied 162 stem analysis trees of Pinus pinea, obtained from even-aged stands distributed throughout the species' range in Spain. From these, 107 trees were felled and analysed in 1966, taken from the 37 permanent plots installed by the INIA (National Institute for Agriculture Research), and the remaining 55 trees were chosen and analysed for this research.

In the 1966 sample, two or three trees were felled and then analysed from each of the 37 permanent plots. From these trees, we have selected those that had a mean diameter at breast height that was included amongst the $20 \%$ of the thickest trees of the plot (Weise criterion for selecting dominant trees [30]). The final number of trees selected was 41 , located in 24 plots. When more than one tree per plot was selected, only one height-growth curve was developed, by taking the highest height value obtained from the trees analysed in the plot at each age.

We felled 55 dominant trees, located in four different geographic regions throughout Spain. The trees were identified and selected close to the temporary production plots, installed by the Department of Silviculture of the CIFOR-INIA between 1992 and 2000, in evenaged stands of Pinus pinea in Northern Plateau, Central Range, West Andalusia and Catalonia. Among all the existing plots (more than 450 ) we chose those with a total age close to or more than 100 years. Since we knew the age and height of the dominant trees, we made an effort to select the plots to cover all possible site qualities. In order to avoid suppressed trees, we refrained from using plots where there were signs of recent harvesting (stumps) because harvested trees may have suppressed the growth of remaining trees.

Once the plots were selected, we looked for a tree in the same stand but outside the plot, whose characteristics were similar to those of the dominant tree in the plot. This tree should be dominant and undamaged. To determine tree age and in order to avoid signs of early suppression or anomaly in growth pattern, we sampled each tree ring growth pattern using a Pressler increment borer. These pre-selected trees were also measured for diameter at breast height, total height, crown height and crown diameter. Distances from the selected tree to the ten nearest trees, as well as the diameter at breast height of these ten trees were also measured.

Chosen trees were felled as close to the ground as possible. The total height of the felled tree was measured, and the stem was divided into sections. Discs were taken from each section, starting at stump height $(10 \mathrm{~cm})$, then at breast height $(1.30 \mathrm{~m})$, and then at every $1.25 \mathrm{~m}$, measured along the stem.

For each disc, annual ring count and growth were measured with a linear positioning digitizer tablet LINTAB, while data obtained were saved and processed with the aid of TSAP software. With these measurements, a small bias occurs as the height at the sectioning point underestimates the real height attained for that year. In order to remove this bias we used the correction proposed by Carmean [7].

The total set of stem analysis data comprises a group of 96 sample trees. The regional location of these trees, as well as the data summary of the sample is presented in table $I$.

\subsection{Validation data set}

Since the suitability and quality of the fit does not necessary reflect the quality of the prediction, we conducted an assessment of the proposed model on a validation data set.

The validation data set we used consists of data from 37 plots of Pinus pinea, found in the set of permanent plots of the Department of Silviculture, CIFOR-INIA, installed in 1966. These plots have been remeasured several times, from 2 to 5 times. No plots were installed on the Pinus pinea stands of Catalonia, so we do not have any validation data from this region.

Permanent plots have a variable number of trees and an area ranging from 750 to $2500 \mathrm{~m}^{2}$. At each measurement the diameter at breast height of all the trees in the plot was measured, while total 


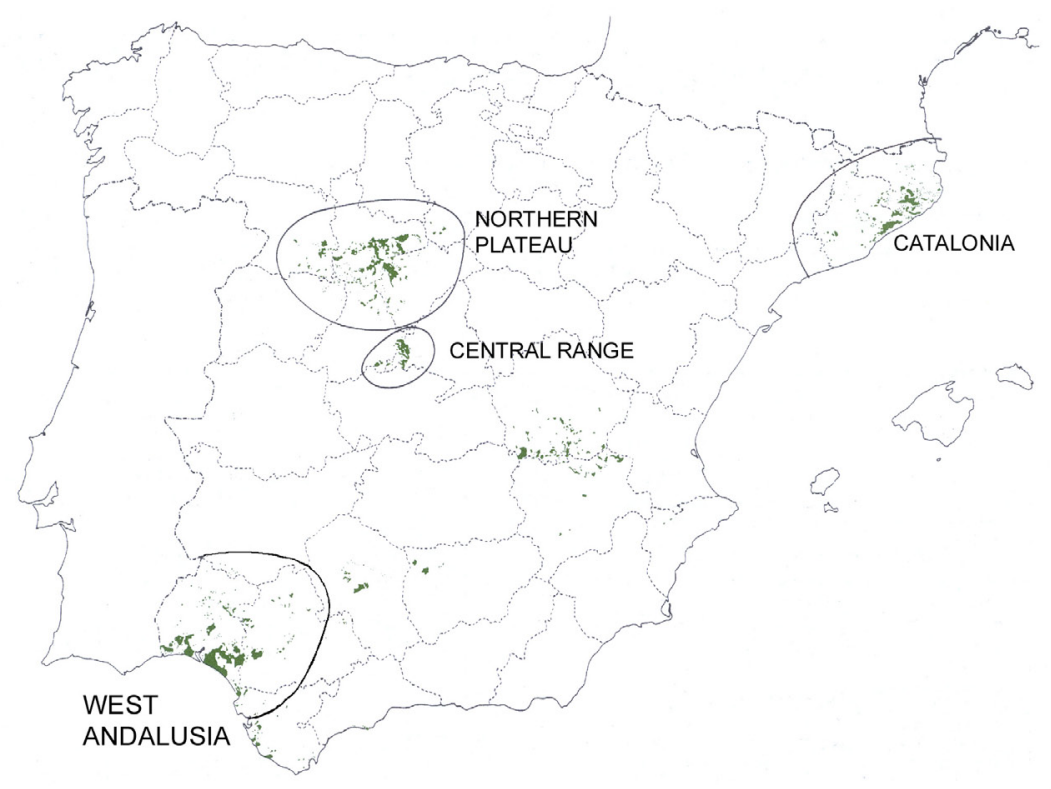

Figure 2. Distribution of the range of Pinus pinea L. in Spain and the sampled regions.

Table I. Summary statistics and sample distribution of stem analysis trees.

\begin{tabular}{lccccccc}
\hline Region & Total & Mean $T$ & SD $T$ & $T$ min-max & Mean Ho & SD Ho & $H$ o min-max \\
\hline West Andalusia & 29 & 60.2 & 24.1 & $20-96$ & 13.45 & 5.14 & $3.8-22.2$ \\
Northern Plateau & 29 & 65.2 & 38.2 & $20-126$ & 10.25 & 5.62 & $3.5-21.2$ \\
Central Range & 27 & 106.8 & 43.2 & $50-214$ & 12.70 & 4.73 & $4.5-19.8$ \\
Catalonia & 11 & 112.6 & 15.0 & $92-137$ & 15.31 & 3.08 & $9.9-19.7$ \\
Total & 96 & 80.8 & 40.6 & $20-214$ & 12.49 & 5.19 & $3.5-22.2$ \\
\hline
\end{tabular}

$T=$ age (years); $H \mathrm{o}=$ dominant height $(\mathrm{m}) ; \mathrm{SD}=$ standard deviation; $\min -\mathrm{max}=$ range.

height was only collected for a sample of 40 trees. Therefore, for each plot and each measurement a function of the type $H=a+b . D+c . D^{2}$, where $H$ is total height and $D$ is diameter at breast height, was fitted to the existing data, and the dominant height was defined as the height of the tree whose diameter is the mean diameter of the $20 \%$ thickest trees in the plot [30], calculated using the above-mentioned function.

\subsection{Methodology}

Many mathematical functions are available $[22,32]$ to model dominant height growth. Desirable characteristics for growth functions are shown in Goelz and Burk [16], and Eflving and Kviste [12]. Among all the techniques developed for building site index curves, we have selected the difference equation method. This method allows us to calculate dominant height at any age based on the data of dominant height at any other age, resulting in models that have the property of invariance with respect to the index age $[3,5,10$, $12,20]$. To meet this objective we use functions of the following type:

$$
H_{2}=\mathrm{f}\left(H_{1}, T_{1}, T_{2}\right)+\varepsilon
$$

where: $H_{1}$ : dominant height at age $T_{1} ; H_{2}$ : dominant height at age $T_{2}$; $\varepsilon:$ additive error.

The main advantages of applying this method are the ability to make use of any temporal series of data, despite its length; the possibility to use data from trees whose total age was under the index age [17] and the fact there is no need to determine an index age prior to fitting the data.

Parameter estimation in fitting this type of function presents several problems. Among these, the most important is related to autocorrelation and lack of independence among observations, which arises from taking several measurements from the same tree at different heights [3, 5, 16, 24]. This may invalidate standard regression hypothesis testing procedures and interval estimations, because error terms are not independent and identically distributed with a common variance. Many approaches to this problem have been developed in different researches [2, 15, 17, 24].

We compared six differential growth functions, selected from the most commonly used in forest research. These functions have been developed, by differentiation and parameter expansion, from wellknown growth functions, such as Richards [27], Schumacher [28], or Korf [30]. The functions we selected are among these reviewed in Cao [6] and Huang [17]. We compared functions with different numbers of parameters, varying between one and four. The selected functions are shown in table II.

\subsection{Data structure}

From each sample stem analysis, we obtained a height-age pair $\left(H_{\mathrm{i}}, T_{\mathrm{i}}\right)$ from each section. The data used for fitting the different 
Table II. Difference equations selected for fitting and comparison.

\begin{tabular}{lll}
\hline Number & Name & \multicolumn{1}{c}{ Function } \\
\hline$(1)$ & Richards & $H_{2}=H_{1} \cdot\left\{\left(1-\exp \left(\mathrm{a} \cdot T_{2}\right)\right) /\left(1-\exp \left(\mathrm{a} \cdot T_{1}\right)\right)\right\}^{\mathrm{b}}$ \\
$(2)$ & Goelz-Burk & $H_{2}=H_{1} \cdot\left\{\left(1-\exp \left(\mathrm{k} \cdot T_{2}\right)\right) /\left(1-\exp \left(\mathrm{k} \cdot T_{1}\right)\right)\right\} \mathrm{d} ; \mathrm{k}=\mathrm{a} \cdot\left(H_{1} / T_{1}\right)^{\mathrm{b}} \cdot T_{1}^{\mathrm{c}}$ \\
$(3)$ & Schumacher & $H_{2}=H_{1} \cdot \exp \left\{\mathrm{a} \cdot\left(1 / T_{2}-1 / T_{1}\right)\right\}$ \\
$(4)$ & Bailey-Clutter & $H_{2}=\exp \left\{\mathrm{a}+\left(\ln \left(H_{1}\right)-\mathrm{a}\right) \cdot\left(T_{2} / T_{1}\right)^{\mathrm{b}}\right\}$ \\
$(5)$ & Clutter-Lenhart & $H_{2}=\exp \left\{\left[\mathrm{a}+\mathrm{b} / T_{2}+\left(\ln \left(H_{1}\right)-\mathrm{a}-\mathrm{b} / T_{1}\right)\right] \cdot \exp \left[\mathrm{c} \cdot\left(1 / T_{2}-1 / T_{1}\right)\right]\right\}$ \\
$(6)$ & Amateis-Burkhart & $H_{2}=\exp \left\{\left[\left(\ln \left(H_{1}\right) \cdot\left(T_{1-} T_{2}\right)^{\mathrm{b}}\right] \cdot \exp \left[\mathrm{a} \cdot\left(1 / T_{2}-1 / T_{1}\right)\right]\right\}\right.$ \\
\hline
\end{tabular}

$H_{\mathrm{i}}$ is dominant height (m) at age $T_{\mathrm{i}}$ (years); a, b, c and d are fitted parameters of the function.

functions was all the possible combinations among height-age pairs for a tree (all possible growth intervals) [5, 16, 17].

In this way, from each tree we get a data series of height-age pairs $\left(H_{\mathrm{i}}, T_{\mathrm{i}}-H_{\mathrm{j}}, T_{\mathrm{j}}\right)$, whose range varies with the age and the height of the tree. Age data refers to total age.

\subsection{Model comparison}

Functions shown in table II were fitted independently to data from each region. The fittings were done using the PROC NLIN procedure on the SAS/STAT software. Fitting was done in a two-step procedure in order to include the autocorrelation correction proposed by Goelz and Burk [16]. In the first step, each function is fitted following ordinary non-linear least squares regression. Then, the error term $e_{\mathrm{ij}}$, residual from estimating $H_{\mathrm{i}}$ using $H_{\mathrm{j}}$, is expanded following an autoregressive process:

$$
e_{\mathrm{ij}}=\rho \cdot \varepsilon_{\mathrm{i}-1, \mathrm{j}}+\gamma \cdot \varepsilon_{\mathrm{i}, \mathrm{j}-1}+\varepsilon_{\mathrm{ij}}
$$

where $\rho$ represents the autocorrelation between the current residual and the residual from estimating $H_{\mathrm{i}-1}$ using $H_{\mathrm{j}}$ as predictor variable $\left(\varepsilon_{\mathrm{i}-1, \mathrm{j}}\right)$, and $\gamma$ represents the autocorrelation between the current residual and the residual from estimating $H_{\mathrm{i}}$ using $H_{\mathrm{j}-1}$ as predictor variable $\left(\varepsilon_{\mathrm{i}, \mathrm{j}-1}\right)$.

In the second step, we fit the expanded function, obtaining $\varepsilon_{\mathrm{ij}}$, which are independent and identically distributed errors with mean zero and constant variance $\eta^{2}$. Knowledge of value of autoregressive parameters $\rho$ and $\gamma$ is of no use for field applications of the resulting site index equations, because the errors $\varepsilon_{\mathrm{i}-1, \mathrm{j}}$ and $\varepsilon_{\mathrm{i}, \mathrm{j}-1}$ cannot be observed without stem analysis [24].

The evaluation of the functions is based on the following criteria:

- Goodness of fit: in each region we calculated the fit statistics sum of squares error (SSE), mean square error (MSE), and modelling efficiency coefficient (EF), a test similar to $R^{2}$ for linear regression. We also used a $t$-test for determining the significance level of the estimated parameters.

$$
\begin{gathered}
\mathrm{SSE}=\sum\left(h_{2 \mathrm{obs}}-h_{2 \text { pred }}\right)^{2} \\
\mathrm{MSE}=\frac{\sum\left(h_{2 \mathrm{obs}}-h_{2 \mathrm{pre}}\right)^{2}}{n-1} \\
\mathrm{EF}=1-\frac{\sum\left(h_{2 \mathrm{obs}}-h_{2 \mathrm{pre}}\right)^{2}}{\sum\left(h_{2 \mathrm{obs}}-h_{2 \mathrm{mean}}\right)^{2}}
\end{gathered}
$$

where $h_{2 \mathrm{obs}}=$ observed height, $h_{2 \text { pre }}=$ predicted height, $h_{2 \text { mean }}=$ mean observed height.
- Residual analysis: for detecting unequal error variance (heteroskedasticity) and the presence of outliers, plots of studentized residuals against predicted heights were made for each region and each function. The existence of significant bias in function fitting was detected by calculating the mean residual error, defined as:

$$
\frac{\sum\left(h_{2 \mathrm{obs}}-h_{2 \mathrm{pre}}\right)}{n}
$$

where: $h_{2 \mathrm{obs}}=$ observed height $h_{2 \text { pre }}=$ predicted height $n=$ total data number.

A $t$-test allows us to determine whether mean residual error differs significantly from zero.

- Validation data: data from the validation set were used to compare predicted height values obtained by applying the functions against real observed values. We compared the mean and percentage value of the error. We also fitted the linear model $H_{\text {observed }}=a+$ $b . H_{\text {predicted }}$, testing whether $a=0$ and $b=1$. We applied a $t$-test, independent for each parameter, and the F-test of Fisher-Snedecor, for the simultaneous test of both parameters.

\subsection{Interregional comparison}

\subsubsection{Homogeneity of parameters test}

Once we selected a unique differential function for describing dominant height, validated it for each region, and estimated the parameters of the function for each region, we determined whether significant differences exist among regional growth patterns.

For this we used two tests for detecting simultaneous homogeneity among parameters, both based on the likelihood-ratio test [13, 19, 29]: the non-linear extra sum of squares $F$ test $[17,18,25]$ and the $\chi^{2}$ test proposed by Lakkis and Jones, in Khattree and Naik [21].

Both methods require the fitting of a full and a reduced model. Full model fitting was done by calculating a different set of parameters for each region. For this fitting, we included dummy variables in the general form of the function as follows:

$$
\mathrm{Y}=\sum V_{\mathrm{i}} f_{\mathrm{i}}
$$

where $\mathrm{i}$ means the given region $(\mathrm{i}=1$ for West Andalusia, $\mathrm{i}=2$ for Northern Plateau, $i=3$ for Central Range, $i=4$ for Catalonia); $f_{\mathrm{i}}$ is the growth function $\mathrm{f}\left(x, \beta_{\mathrm{i}}\right)$ fitted for region $\mathrm{i}$; and $V_{\mathrm{i}}$ is a dummy variable whose value is 1 if the data is from region $i$, and 0 if it is from other region.

In the reduced model we assumed that the vectors of parameters are equal for all the regions $\left(\beta_{1}=\beta_{2}=\beta_{3}=\beta_{4}\right)$, making a unique fit of the function $\mathrm{f}(x, \beta)$ to all the regions in the data set. 
Table III. Regional groups proposed for error analysis.

\begin{tabular}{llr}
\hline Regional group & Null hypotheses & Combined regions \\
\hline A & $\beta_{1} \neq \beta_{2} \neq \beta_{3} \neq \beta_{4}$ & All regions separated \\
B & $\beta_{1}=\beta_{2}=\beta_{3}=\beta_{4}$ & All regions combined \\
C & $\beta_{1} \neq \beta_{2}=\beta_{3}=\beta_{4}$ & Central Range, Northern Plateau, Catalonia \\
D & $\beta_{1}=\beta_{2}=\beta_{4} \neq \beta_{3}$ & West Andalusia, Northern Plateau, Catalonia \\
E & $\beta_{1}=\beta_{3}=\beta_{4} \neq \beta_{2}$ & West Andalusia, Central Range, Catalonia \\
F & $\beta_{1}=\beta_{2}=\beta_{3} \neq \beta_{4}$ & West Andalusia, Central Range, Northern Plateau \\
G & $\beta_{1}=\beta_{2} \neq \beta_{3} \neq \beta_{4}$ & Northern Plateau, West Andalusia \\
H & $\beta_{1}=\beta_{3} \neq \beta_{2} \neq \beta_{4}$ & West Andalusia, Central Range \\
I & $\beta_{1} \neq \beta_{2}=\beta_{3} \neq \beta_{4}$ & Northern Plateau, Central Range \\
J & $\beta_{1}=\beta_{4} \neq \beta_{2} \neq \beta_{3}$ & West Andalusia, Catalonia \\
K & $\beta_{1} \neq \beta_{2}=\beta_{4} \neq \beta_{3}$ & Northern Plateau, Catalonia \\
L & $\beta_{1} \neq \beta_{2} \neq \beta_{3}=\beta_{4}$ & Central Range, Catalonia \\
\hline$\beta$
\end{tabular}

$\beta_{\mathrm{i}}=$ vector of parameters for region $\mathrm{i}$.

Equality of both models is tested by considering the following hypotheses:

Ho: vector of parameters $\beta_{\mathrm{i}}$ are equal for all the regions against

$H_{1}$ : at least one of the equalities of $H$ o is not true.

Lakkis-Jones test uses the $L$ statistic defined as:

$$
L=\left(\frac{S S_{\mathrm{f}}}{S S_{\mathrm{r}}}\right)^{n / 2}
$$

where: $S S_{\mathrm{f}}=$ sum of squares error for full model; $S S_{\mathrm{r}}=$ sum of squares error for reduced model; and $n=$ total number of observations.

If homogeneity exists among the regional vectors of parameters $\beta$, the distribution of the statistic $-2 \cdot \ln (L)$ converges in probability to a Pearson $\chi^{2}$ distribution, with $v$ degrees of freedom, where $v$ is equal to the difference between the number of parameters estimated in the full and the reduced models. In this case we cannot reject the null hypotheses of equality of parameters.

The F-test uses the following statistic:

$$
F=\frac{\left(\frac{S S_{\mathrm{r}}-S S_{\mathrm{f}}}{d f_{\mathrm{r}}-d f_{\mathrm{f}}}\right)}{\left(\frac{S S_{\mathrm{f}}}{d f_{\mathrm{f}}}\right)}
$$

where $S S_{\mathrm{f}}=$ sum of squares error for full model; $S S_{\mathrm{r}}=$ sum of squares error for reduced model; $d f_{\mathrm{f}}=$ degrees of freedom for full model; and $d f_{\mathrm{r}}=$ degrees of freedom for reduced model.

The statistical decision rule at the given significance $\alpha$ level is:

If $F>\mathrm{F}_{\text {Fisher-Snedecor }}\left(1-\alpha ; d f_{\mathrm{r}}-d f_{\mathrm{f}} ; d f_{\mathrm{f}}\right)$, we reject the null hypotheses $H \mathrm{o}$, which then means that separate models are required for each region.

If $F<\mathrm{F}_{\text {Fisher-Snedecor }}\left(1-\alpha ; d f_{\mathrm{r}}-d f_{\mathrm{f}} ; d f_{\mathrm{f}}\right)$, we cannot reject the null hypotheses $H \mathrm{o}$, accepting then that the reduced model is appropriate for all regions.

If the homogeneity of parameters tests reveal significant differences among regions, these may be caused by the variability existing among two or more of these regions. Taking this into account, it is advisable to apply the tests to all the possible combinations of regions [18]. This will allow us to identify, region by region, the source of difference and the degree of similarity in growth patterns.

\subsubsection{Error analysis}

If the homogeneity of parameters tests reveal the existence of significant differences among regional dominant height growth patterns, we next determine the precision level obtained by fitting the selected function to the combined data from different regional groups $[1,11]$.

We define twelve different regional groups. We let: $\beta_{1}=$ vector of parameters for West Andalusia; $\beta_{2}=$ vector of parameters for Northern Plateau; $\beta_{3}=$ vector of parameters for Central Range; $\beta_{4}=$ vector of parameters for Catalonia; and we define the regional combinations shown in table III.

For each of the regional groups, we fit the selected function, taking into account the assumptions imposed by its null hypotheses. This means that, for example, in B group we fit the model to the total data set, while in $\mathrm{C}$ group, we will fit the model to the combined data from Central Range, Northern Plateau and Catalonia, and make an independent fit to the data from West Andalusia. Parameter estimates for group A coincides with those obtained in the separate fitting made for each region.

For each regional group, we calculate the value of the sum of squares error and mean error. A $t$-test will determine whether mean error differs significantly from zero. In order to detect if there is an unequal distribution of the error with the predictor age, we divide the data set into six classes of predictor age. All possible pairs $\left(H_{\mathrm{i}}, T_{\mathrm{i}-}\right.$ $H_{\mathrm{j}}, T_{\mathrm{j}}$ ) developed from the data set are grouped into the following predictor age classes: $0-20,20-40,40-60,60-80,80-100$ and more than 100 years. We also evaluated the distribution of the error with the absolute value of the length of the interval of prediction $\left|T_{\mathrm{j}}-T_{\mathrm{i}}\right|$. For this case we also grouped data into six twenty-year interval classes. An indication of the prediction power of the model is given by the modelling efficiency coefficient EF.

Together with the value of the mean absolute error calculated for the different regional models, we determine the value of the error committed in applying any of the regional groups instead of group A (separate regions). For doing this, we define a new variable comparison error (comperr) defined as follows:

$$
\text { comperr }_{\mathrm{i}}=\mathrm{H}_{2 \text { pred ModA }}-H_{2 \text { pred Modi }}
$$


Table IV. Fit statistics and summary results for the regional fit of the functions.

\begin{tabular}{|c|c|c|c|c|c|c|c|c|c|}
\hline \multirow[t]{2}{*}{ Region } & \multirow[t]{2}{*}{ Function } & \multicolumn{4}{|c|}{ Parameter estimates } & \multirow[t]{2}{*}{ SSE } & \multirow[t]{2}{*}{ MSE } & \multirow[t]{2}{*}{$\mathrm{EF}$} & \multirow[t]{2}{*}{ Error } \\
\hline & & $\mathrm{a}$ & $\mathrm{b}$ & $\mathrm{c}$ & $\mathrm{d}$ & & & & \\
\hline \multirow[t]{6}{*}{ West Andalusia } & (1) & -0.0259 & 1.2127 & & & 557.7 & 0.3162 & 98.93 & $0.021^{1}$ \\
\hline & (2) & 0.0781 & 0.7380 & -0.0415 & 1.3801 & 455.6 & 0.2586 & 99.12 & $0.005^{1}$ \\
\hline & (3) & -9.6034 & & & & 2520.5 & 1.4280 & 95.15 & 0.322 \\
\hline & (4) & 3.8290 & -0.5199 & & & 519.1 & 0.2943 & 99.00 & $-0.026^{2}$ \\
\hline & (5) & 2.5125 & -26.4537 & 6.3112 & & 780.6 & 0.4428 & 98.50 & 0.041 \\
\hline & (6) & -5.6487 & -0.0952 & & & 1086.9 & 0.6162 & 97.91 & 0.086 \\
\hline \multirow[t]{6}{*}{ Northern Plateau } & (1) & -0.0106 & 1.0158 & & & 492.8 & 0.2889 & 98.94 & 0.033 \\
\hline & (2) & 0.0577 & 0.7397 & -0.0671 & 1.1700 & 423.1 & 0.2483 & 99.09 & $0.002^{1}$ \\
\hline & (3) & -13.5977 & & & & 1615.4 & 0.9463 & 96.53 & 0.289 \\
\hline & (4) & 5.2613 & -0.2576 & & & 427.8 & 0.2507 & 99.08 & $0.011^{1}$ \\
\hline & (5) & -4.6927 & -61.4854 & 3.9962 & & 1038.2 & 0.6089 & 97.77 & 0.088 \\
\hline & (6) & -6.7607 & -0.1564 & & & 783.0 & 0.4590 & 98.32 & 0.098 \\
\hline \multirow[t]{6}{*}{ Central Range } & (1) & -0.0066 & 0.8324 & & & 452.0 & 0.2274 & 99.11 & $0.023^{1}$ \\
\hline & (2) & 0.0829 & 1.2179 & 0.0742 & 1.1391 & 311.5 & 0.1569 & 99.38 & $-0.013^{1}$ \\
\hline & (3) & -12.1916 & & & & 1932.5 & 0.9716 & 96.18 & 0.256 \\
\hline & (4) & 4.0410 & -0.3844 & & & 275.2 & 0.1384 & 99.46 & $0.006^{1}$ \\
\hline & (5) & 0.9562 & -39.8553 & 6.0713 & & 1144.9 & 0.5762 & 97.74 & 0.053 \\
\hline & (6) & -3.0618 & -0.1927 & & & 926.0 & 0.4658 & 98.17 & 0.099 \\
\hline \multirow[t]{6}{*}{ Catalonia } & (1) & -0.0068 & 0.8865 & & & 464.9 & 0.3189 & 98.69 & $0.003^{1}$ \\
\hline & (2) & 0.1963 & 1.3331 & -0.0778 & 1.2960 & 344.9 & 0.2369 & 99.03 & $0.002^{1}$ \\
\hline & (3) & -9.3972 & & & & 2222.1 & 1.5231 & 93.74 & 0.302 \\
\hline & (4) & 4.0352 & -0.4138 & & & 446.3 & 0.3061 & 98.74 & $0.0003^{1}$ \\
\hline & (5) & -3.4086 & -50.0101 & 3.5056 & & 1229.4 & 0.8348 & 96.54 & 0.143 \\
\hline & (6) & -4.1318 & -0.2127 & & & 668.3 & 0.4583 & 98.12 & 0.059 \\
\hline
\end{tabular}

${ }^{1}$ Not significant with $P>0.05 ;{ }^{2}$ not significant with $0.05>P>0.01$. SSE $=$ error sum of squares; $\mathrm{MSE}=$ mean squared error; $\mathrm{EF}=$ modelling efficiency coefficient; Error $=$ mean residual error.

where: comperr $_{\mathrm{i}}=$ Residual obtained when applying model $\mathrm{i}$ instead of model A; $\mathrm{H}_{2 \text { pred ModA }}=$ Predicted height obtained from model A; and $H_{2 \text { pred Modi }}=$ Predicted height obtained from model i.

We calculate the mean value for this variable, and we used a $t$-test for determining the significance degree of mean relative error value for each regional group.

\section{RESULTS}

\subsection{Model comparison}

The results of fitting the functions for each region are shown in table $I V$. A $t$-test reveals that parameters estimates for all functions are significant at an $\alpha$ level of 5\%. The analysis of the fit statistics reveals that smaller SSE and MSE values are always shown by functions (1), (2) and (4), and are much higher for the rest of functions compared. Plots of residuals against predicted height values show that the variance is constant (homoscedastic) for any function, but we detected the presence of outlier, meaningless values (negative heights) and bias when applying functions (3), (5) and (6). Finally, an analysis of the mean error value reveals the existence of significant bias, at a significance level of $1 \%$, in fitting regional data to functions (1), (3), (5) and (6). The best fit is obtained in using functions (1), (2) and (4).

Next, we used the validation data set to evaluate prediction performance of the different functions tested. We compared the real height values from the validation data set with those predicted by applying the tested functions with the parameters estimated for each region. All the functions show a mean error of less than $1 \%$ for any regional fit of the validation data. Among the three best functions based on a good fit ((1), (2) and (4)), function (4) is the only one with a significance level of $1 \%$, for both tests for determining whether $a=0$ and $b=1$ for the three regional validation data sets.

From these results, we recommend using function (4), a differential form of the Korf growth function [23], developed 
Table V. $L$ and $F$ statistics and tests for grouped regions.

\begin{tabular}{lcclcc}
\hline Regional groups & $n$ & $L$ & $P>L$ & $F$ & \multicolumn{1}{c}{$P>F$} \\
\hline All combined & 6932 & 578.467 & $4.190 \mathrm{E}-116$ & 50.158 & $6.587 \mathrm{E}-116$ \\
Central R. - N. Plateau - Catalonia & 5164 & 95.270 & $3.942 \mathrm{E}-17$ & 41.991 & $4.261 \mathrm{E}-17$ \\
W. Andalusia - Central R. - Catalonia & 5222 & 495.566 & $6.287 \mathrm{E}-102$ & 64.831 & $9.598 \mathrm{E}-102$ \\
W. Andalusia - Catalonia - N. Plateau & 4940 & 366.853 & $2.281 \mathrm{E}-74$ & 47.487 & $3.171 \mathrm{E}-74$ \\
W. Andalusia - N. Plateau - Central R. & 5470 & 582.003 & $1.728 \mathrm{E}-120$ & 76.593 & $2.780 \mathrm{E}-120$ \\
W. Andalusia - N. Plateau & 3478 & 295.946 & $8.112 \mathrm{E}-63$ & 77.048 & $1.090 \mathrm{E}-62$ \\
W. Andalusia - Central R. & 3760 & 487.256 & $3.821 \mathrm{E}-104$ & 129.782 & $6.008 \mathrm{E}-104$ \\
N. Plateau - Central R. & 3702 & 94.622 & $1.371 \mathrm{E}-19$ & 23.909 & $1.497 \mathrm{E}-19$ \\
W. Andalusia - Catalonia & 3230 & 231.954 & $5.010 \mathrm{E}-49$ & 59.973 & $6.430 \mathrm{E}-49$ \\
N. Plateau - Catalonia & 3172 & 1.814 & 0.769 & 0.452 & 0.770 \\
Central R. - Catalonia & 3454 & 35.245 & $4.136 \mathrm{E}-07$ & 8.836 & $4.278 \mathrm{E}-07$ \\
\hline
\end{tabular}

$L=$ Lakkis Jones statistic (6); $F=$ non linear extra sum of squares statistic (7); $P>L=$ probability for $L$ to be under a Pearson $\chi^{2}$ distribution, with $d f \mathrm{r}-d f \mathrm{f}$ degrees of freedom; $P>F$ probability for $F$ to be under a Fisher Snedecor F distribution with $d f \mathrm{r}-d f f$; $d f \mathrm{f}$ degrees of freedom.

by Bailey and Clutter [2]. This function presents reasonably good results for goodness of fit statistics in model fitting and in validation. It does not show any significant problem with heteroskedasticty or prediction bias. We selected this function instead of function (2), a differential form of the Richards [27] function developed by Goelz and Burk [16], which showed better results in fitting statistics. We did this because the Bailey-Clutter function has a smaller number of parameters to estimate (two vs. four). Furthermore, the Goelz-Burk function is not a true base-age invariant function, on account of being a non-reciprocal difference equation [17]. This means that the choice of different predictor (age-height) pairs may have an impact on height prediction.

Applying the Bailey-Clutter function also allowed us to verify the property of polymorphism. Let the general expression of Korf growth function be:

$$
H_{\mathrm{i}}=\exp \left(a+b \cdot\left(\frac{1}{T_{\mathrm{i}}}\right)^{c}\right) .
$$

The relative rate of growth, $(\mathrm{d} H / \mathrm{d} T) / H$, is related to both " $b$ " and " $c$ ". Bailey and Clutter considered the regression slope parameter " $b$ " as a site specific parameter, relating it to the predictor age and dominant height at that age $[2,6]$ by the following expression:

$$
b=\left[\log \left(H_{\mathrm{j}}\right)-a\right] \cdot T_{\mathrm{j}}^{\mathrm{c}} .
$$

As the relative rate of growth is function of " $b$ ", it is not constant throughout the sites. Different rates of growth for different sites means polymorphism in site index curves.

A graphical representation of the selected function, fitted for each region, and forced to pass through age-height pairs $(100,9),(100,13),(100,17)$ and $(100,21)$ determines the regional site index curves for the species (figure 3).

\subsection{Interregional comparison}

The regional site index curves (figure 3) show a clear trend towards equality in dominant height growth pattern among different stands found in Northern Plateau, Central Range,

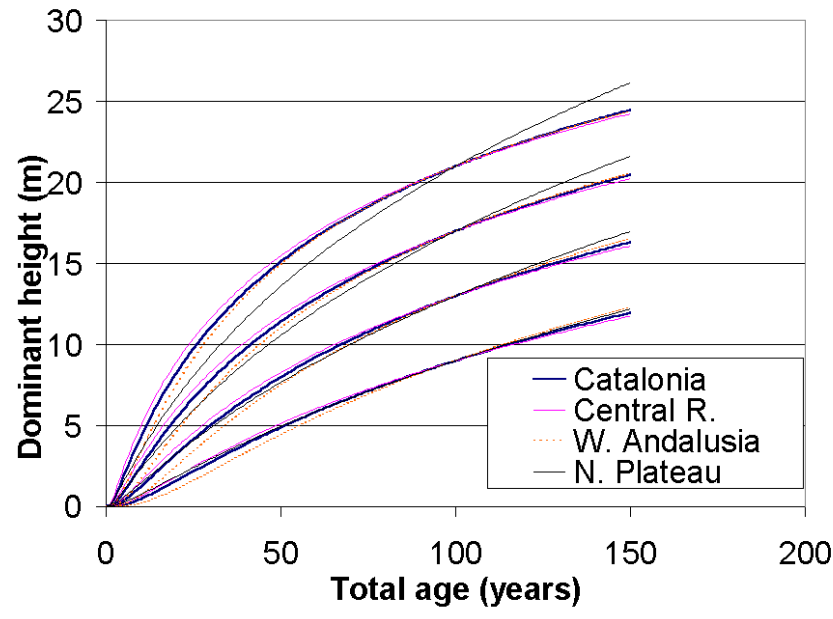

Figure 3. Regional site index curves for Pinus pinea L. in Spain using the Bailey-Clutter function.

West Andalusia and Catalonia. We only detect important differences in growth patterns for highest site index class in the Northern Plateau region, which may be a result of the small number of trees of this class in this region.

\subsubsection{Homogeneity of parameters tests}

For the statistical analysis of interregional variability in dominant height growth pattern, we first fit the reduced model and full model to the complete data set and to each one of the regional combination data sets. The value of the $\mathrm{L}$ statistic (6) for Lakkis-Jones test, and F statistic (7) for the non-linear extra sum of squares test are shown in table $V$.

At a significance level $\alpha=5 \%$, we cannot reject the null hypotheses of parameters homogeneity for comparison between Catalonia and Northern Plateau. For the rest of regional groups compared we can reject null hypotheses. 
Table VI. Mean absolute error analysis obtained by fitting function (4) to the different regional groups. Distribution with predictor age.

\begin{tabular}{|c|c|c|c|c|c|c|c|c|}
\hline \multicolumn{2}{|c|}{ Predictor age class } & \multirow{2}{*}{$\begin{array}{r}\text { Total } \\
6932\end{array}$} & \multirow{2}{*}{$\begin{array}{c}0-20 \\
1852\end{array}$} & \multirow{2}{*}{$\begin{array}{r}20-40 \\
1894\end{array}$} & \multirow{2}{*}{$\begin{array}{r}40-60 \\
1220\end{array}$} & \multirow{2}{*}{$\begin{array}{r}60-80 \\
789\end{array}$} & \multirow{2}{*}{$\begin{array}{c}80-100 \\
573\end{array}$} & \multirow{2}{*}{$\begin{array}{r}>100 \\
604\end{array}$} \\
\hline Group & $\mathrm{n}$ & & & & & & & \\
\hline A & Error & $-0.007^{1}$ & $0.085^{1}$ & $0.045^{1}$ & $-0.096^{3}$ & $-0.067^{2}$ & $0.018^{1}$ & -0.225 \\
\hline B & Error & $-0.009^{1}$ & $0.146^{3}$ & $-0.002^{1}$ & -0.163 & -0.129 & $-0.039^{1}$ & $-0.012^{1}$ \\
\hline $\mathrm{C}$ & Error & $-0.009^{1}$ & $0.085^{1}$ & $0.063^{2}$ & -0.112 & -0.145 & $-0.056^{1}$ & $-0.096^{2}$ \\
\hline $\mathrm{D}$ & Error & $-0.007^{1}$ & $0.122^{3}$ & $0.010^{1}$ & -0.115 & $-0.084^{3}$ & $0.017^{1}$ & -0.164 \\
\hline $\mathrm{E}$ & Error & $-0.008^{1}$ & $0.155^{3}$ & $-0.021^{1}$ & -0.178 & $-0.078^{2}$ & $0.005^{1}$ & $-0.047^{1}$ \\
\hline $\mathrm{F}$ & Error & $-0.010^{1}$ & $0.138^{3}$ & $0.000^{1}$ & -0.157 & -0.127 & $-0.044^{1}$ & $-0.022^{1}$ \\
\hline G & Error & $-0.008^{1}$ & $0.096^{2}$ & $0.027^{1}$ & $-0.089^{3}$ & $-0.073^{2}$ & $0.008^{1}$ & -0.215 \\
\hline $\mathrm{H}$ & Error & $-0.007^{1}$ & $0.156^{3}$ & $-0.020^{1}$ & -0.179 & $-0.079^{2}$ & $0.005^{1}$ & $-0.045^{1}$ \\
\hline I & Error & $-0.012^{1}$ & $0.077^{1}$ & $0.060^{2}$ & -0.109 & -0.141 & $-0.056^{1}$ & $-0.105^{2}$ \\
\hline $\mathrm{J}$ & Error & $-0.010^{1}$ & $0.113^{2}$ & $0.003^{1}$ & -0.131 & $-0.059^{1}$ & $0.037^{1}$ & -0.170 \\
\hline $\mathrm{K}$ & Error & $-0.002^{1}$ & $0.104^{2}$ & $0.050^{2}$ & $-0.107^{3}$ & $-0.097^{3}$ & $0.013^{1}$ & -0.181 \\
\hline $\mathrm{L}$ & Error & $-0.007^{1}$ & $0.084^{1}$ & $0.052^{2}$ & $-0.098^{3}$ & $-0.077^{2}$ & $-0.005^{1}$ & -0.201 \\
\hline
\end{tabular}

${ }^{1}$ Not significant with $P>0.05 ;{ }^{2}$ not significant with $0.05>P>0.01 ;{ }^{3}$ not significant with $0.01>P>0.001 ; n=$ total data number; error $=\sum\left(H_{2}\right.$ pre $-H_{2}$ obs $) / n$.

Table VII. Mean absolute error analysis obtained by fitting function (4) to the different regional groups. Distribution with prediction interval length class $\left|T_{\mathrm{j}}-T_{\mathrm{i}}\right|$.

\begin{tabular}{lcccccccc}
\hline Interval prediction class & Total & $0-20$ & $20-40$ & $40-60$ & $60-80$ & $80-100$ & \multicolumn{1}{c}{$>100$} \\
\hline Group & $\mathrm{n}$ & 6932 & 2630 & 1904 & 1140 & 716 & 358 \\
$\mathrm{~A}$ & Error & $-0.007^{1}$ & $-0.001^{1}$ & $0.016^{1}$ & $-0.001^{1}$ & $-0.050^{1}$ & $-0.084^{1}$ & $-0.086^{1}$ \\
B & Error & $-0.009^{1}$ & $0.018^{1}$ & $0.044^{1}$ & $-0.004^{1}$ & $-0.078^{1}$ & $-0.187^{1}$ & $-0.383^{2}$ \\
C & Error & $-0.009^{1}$ & $-0.001^{1}$ & $0.015^{1}$ & $0.005^{1}$ & $-0.039^{1}$ & $-0.094^{1}$ & $-0.194^{1}$ \\
D & Error & $-0.007^{1}$ & $0.012^{1}$ & $0.035^{1}$ & $-0.014^{1}$ & $-0.076^{1}$ & $-0.147^{1}$ & $-0.145^{1}$ \\
E & Error & $-0.008^{1}$ & $0.018^{1}$ & $0.045^{1}$ & $-0.001^{1}$ & $-0.081^{1}$ & $-0.180^{1}$ & $-0.381^{2}$ \\
F & Error & $-0.010^{1}$ & $0.017^{1}$ & $0.043^{1}$ & $-0.005^{1}$ & $-0.080^{1}$ & $-0.190^{1}$ & $-0.393^{2}$ \\
G & Error & $-0.008^{1}$ & $0.010^{1}$ & $0.030^{1}$ & $-0.017^{1}$ & $-0.076^{1}$ & $-0.124^{1}$ & $-0.134^{1}$ \\
H & Error & $-0.007^{1}$ & $0.018^{1}$ & $0.045^{1}$ & $0.001^{1}$ & $-0.079^{1}$ & $-0.177^{1}$ & $-0.380^{2}$ \\
I & Error & $-0.012^{1}$ & $-0.002^{1}$ & $0.013^{1}$ & $0.002^{1}$ & $-0.042^{1}$ & $-0.111^{1}$ & $-0.182^{1}$ \\
J & Error & $-0.010^{1}$ & $0.006^{1}$ & $0.027^{1}$ & $-0.009^{1}$ & $-0.070^{1}$ & $-0.146^{1}$ & $-0.145^{1}$ \\
K & Error & $-0.002^{1}$ & $0.001^{1}$ & $0.019^{1}$ & $0.005^{1}$ & $-0.039^{1}$ & $-0.073^{1}$ & $-0.062^{1}$ \\
L & Error & $-0.007^{1}$ & $0.001^{1}$ & $0.017^{1}$ & $0.002^{1}$ & $-0.048^{1}$ & $-0.077^{1}$ & $-0.153^{1}$ \\
\hline
\end{tabular}

${ }^{1}$ Not significant with $P>0.05 ;{ }^{2}$ not significant with $0.05>P>0.01 ;{ }^{3}$ not significant with $0.01>P>0.001 ; n=$ total data number; Error $=\Sigma\left(H_{2}\right.$ pre $-H_{2}$ obs $) / n$.

\subsubsection{Error analysis}

After we detected the existence of significant differences among regional site index curves for Pinus pinea, we tried to determine the real value of this difference. We fit the BaileyClutter function to the twelve regional groups defined in table III.

The mean error, the significance level of the mean error, and the distribution of the error against predictor age are shown in table VI. Results for the distribution of these statistics against prediction interval length are shown in table VII.
Results indicate that in the fit of the function to the regional groups, the mean error value does not differ significantly from zero at a level $\alpha=5 \%$. The variability of this error with predictor age shows that, for all the groups, only the range of predictor age between 40 and 80 years leads to significant errors, although the mean value of the error never exceeds $20 \mathrm{~cm}$. When evaluating this error with prediction interval length, we found that, except for the largest interval (more than 100 years between predictor and predicted age), mean error does not differ significantly from zero. 
Table VIII. Summary results for the modelling efficiency coefficient EF analysis and mean relative error comperr analysis (obtained by applying each regional group instead of group A).

\begin{tabular}{ccc}
\hline Group & EF $(\%)$ & Comperr \\
\hline A & 93.21 & - \\
B & 92.02 & $0.001^{1}$ \\
C & 92.76 & $0.001^{1}$ \\
D & 92.68 & $-0.0004^{1}$ \\
E & 92.22 & $0.001^{1}$ \\
F & 92.03 & $0.003^{1}$ \\
G & 92.80 & $0.001^{1}$ \\
H & 92.23 & $0.0002^{1}$ \\
I & 92.81 & $0.004^{1}$ \\
J & 92.92 & $0.002^{1}$ \\
K & 93.11 & $-0.004^{2}$ \\
L & 93.06 & $-0.0001^{1}$ \\
\hline
\end{tabular}

${ }^{1}$ Not significant with $P>0.05 ;{ }^{2}$ not significant with $0.05>P>0.01$.

The EF statistic for the different regional models is included in table VIII. Modelling efficiency coefficient EF has the highest value, logically, for A group (separate regions). In any case, the EF value varies between $93.21 \%$ for the highest (A group) and $92.02 \%$ for the lowest (B group, combining all the regions together), and does not show a great difference among groups. Results from the evaluation of the modelling efficiency with both predictor age and prediction interval length for the A (separate regions) and B (combined regions) are shown in figure 4. The results for the rest of regional groups involved are between the values for A and B groups.

Table VIII also shows the mean relative error committed in applying each regional model instead of model A (separate regions), as well as the significance level of this error. In this analysis we detected that, for a significance level $\alpha=5 \%$, there are no differences for the mean error between model A and the rest of the models, except model K.

\section{DISCUSSION AND CONCLUSIONS}

\subsection{Model comparison}

Among the six differential growth equations evaluated for describing dominant height growth patterns in Pinus pinea, a differential form of the growth function proposed by Korf [23], developed by Bailey and Clutter [2], has been selected. This function was the best in explaining dominant height growth pattern for the species in all the regions compared. In fitting this function to our data, we have developed regional site index equations for Pinus pinea, and validated them using data from permanent plots installed by INIA during the sixties.

The use of homogeneous data, collected in a uniform way in each one of the regions compared, and the use of a unique function, fitted to each set of regional data, shows us that a large part of the difference detected among site index curves for Pinus pinea published in Spain is caused by the lack of homogeneity and uniformity in data collection and data processing.

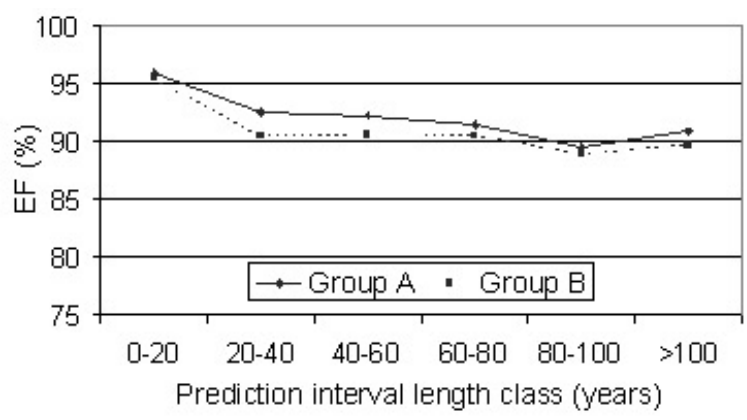

(a)

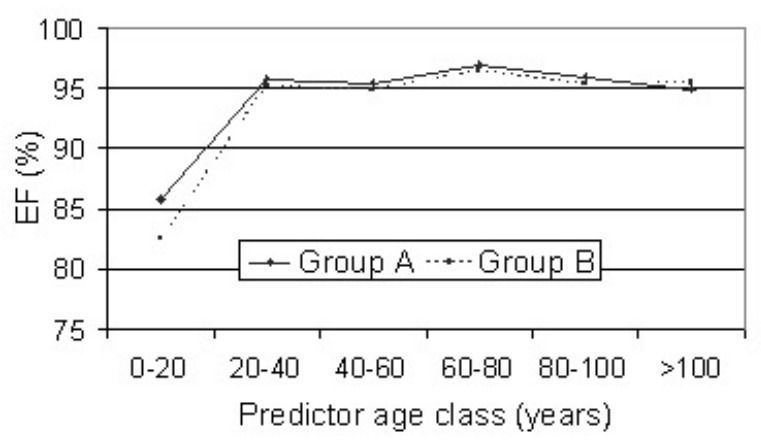

(b)

Figure 4. Analysis of modelling efficiency variability with prediction interval length (a) and predictor age (b).

The variable chosen as independent has been the total age. The use of breast height age has been proposed by many authors for the development of site index curves and height growth models [8-10, 16, 24]. Despite this, Beland and Bergeron [4] argue that ignoring the first years of plant growth might obscure the differences existing between regional or ecological areas in terms of level of site index, curve shape or growth pattern. The same reasoning is used by Johansson [20], Duplat and Tran-Ha [11], and Elfving and Kiviste [12].

\subsection{Interregional comparison}

A graphical comparison among regional site index curves (figure 3) indicates that there is a high level of similarity between dominant height growth patterns for the four different Spanish regions tested, especially for ages over 40 . We only find differences in the growth pattern of the highest site index curve for Northern Plateau stands. We consider that this difference may be caused by the small number of trees in this class used in fitting the function.

The use of two statistical tests to determine homogeneity of parameters, when comparing non-linear functions (non-linear extra sum of squares F-test and Lakkis Jones test), shows the existence of significant differences among regional growth patterns, except for the regional pair Catalonia-Northern Plateau. This result does seem not to be in keeping with the graphical representation of the regional curves (figure 3), where all the regions' patterns are similar. A reason for this could be based on the power of the homogeneity of parameters tests used, both derived from the likelihood ratio test. As stated by Gallant [13], with large samples , as is our case, the power 
of the likelihood ratio test becomes so high than small differences are identified as significant.

An analysis of the mean prediction error to determine the existence of differences among regional height growth models has been used in developing national site index curves for Picea glauca (Moench) Voss in Canada [1], and in the study of interregional variability in site index curves for Quercus petraea in France [11]. We have applied this method to different models based on regional grouping.

The analysis of both the mean absolute error and the modelling efficiency coefficient, reveals that there are no major differences among the different regional models. The most interesting finding is that the error is not equally distributed amongst the different predictor age classes, being higher in the youngest class ( $0-20$ years old). Regarding the distribution of the error with the length of the prediction interval, the smallest error is found when prediction interval is below 20 years. When intervals are larger, error trends to increase, but not in a very pronounced pattern. This confirms the difficulty and the lack of precision in prediction in using height growth models at younger ages of the stand with very large intervals for prediction.

The differences detected in the analysis of the mean comparison error (the difference between predicted height obtained with model A and the value obtained in applying other models) are so small that they allow us to justify the use of each of the regional models proposed.

We propose the selection of model B, obtained by fitting the Bailey-Clutter function to the total data set from the four regions studied, considered as a unique group. Application of this model, unique for the four regions, results in a mean prediction error that does not differ significantly, at a $\alpha$ level of 5\%, from zero. The study of the variability of this error with both predictor age and prediction interval length shows that it is not significant, with $\alpha$ level $>0.1 \%$, for all the ranges involved. This value is similar to those obtained for the rest of regional models (including model $\mathrm{A}$, separate regions). In the same way, the modelling efficiency coefficient calculated for model B (all regions combined) is $92.02 \%$, which is $1.2 \%$ less than the EF value calculated for model A of separate regions.

At a significance level of $5 \%$, the results show that there are no differences between the mean error obtained in applying models A (separate regions) and B (combined regions).

To adopt a unique interregional model means a decrease in the prediction power of the model, as compared to the models for separate regions. The value of this decrease, estimated by the modelling efficiency coefficient, is about $1 \%$. This decrease seems to be acceptable if we compare it to the advantages of having one model for classifying site quality in forest stands of Pinus pinea in the four regions studied. Forest managers will benefit from the adoption of one model for site index, because this will allow them to:

- Compare the productive capacity among stands located in different regions.

- Take advantage of the previous experience developed in forest management of stands located in different regions, but with similar quality.

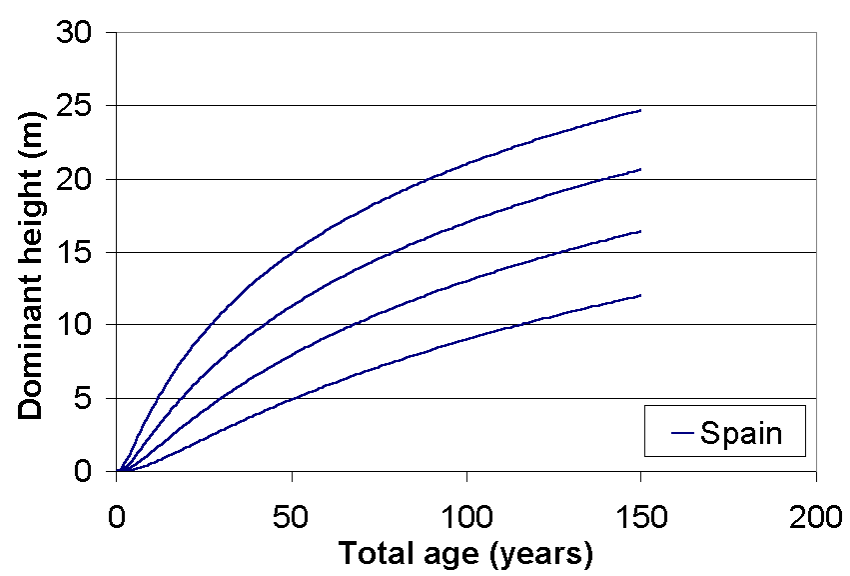

Figure 5. Interregional site index curves for Pinus pinea L. in Spain.

- Apply treatments and silviculture models already tested in other regions.

- Study the viability of developing interregional growth, competition and production models for the species.

The model proposed has a geographic validity, which comprises the four studied regions. The fact that these regions include most of the area where the species occurs in Spain, lead us to propose it as a site index model for Pinus pinea for the whole state.

The general form of the national site index equation proposed for Pinus pinea is:

$$
H_{2}=\exp \left\{4.1437+\left(\ln \left(H_{1}\right)-4.1437\right)\left(\frac{T_{2}}{T_{1}}\right)^{-0.3935}\right\}
$$

where $H_{\mathrm{i}}$ is dominant height (in meters) for the stand at age $T_{\mathrm{i}}$ (in years).

Graphical representation of this model defines the national site index curves for Pinus pinea, forced to pass through the points $(100,21),(100,17),(100,13)$ and $(100,9)$ as shown in figure 5 .

Acknowledgements: The authors wish to thank Nikos Nanos, for reviewing the manuscript and for his helpful comments. We also want to thank Jesús de Miguel, for his help with the figures. We are also grateful to two anonymous referees, for their valuable comments on the manuscript. The research was partially supported by a grant to the corresponding author from the Consejería de Educación, Comunidad de Madrid, in the context of the INIA project SC-99-017.

\section{REFERENCES}

[1] Alemdag I.S., National site-index and height growth curves for white spruce growing in natural stands in Canada, Can. J. For. Res. 21 (1991) 1466-1474.

[2] Bailey R.L., Clutter J.L., Base-age invariant polymorphic site curve, For. Sci. 20 (1974) 155-159. 
[3] Beaumont J.F., Ung C.H., Bernier-Cardou M., Relating site index to ecological factors in black spruce stands: tests of hypotheses, For. Sci. 45 (1999) 484-491.

[4] Beland M., Bergeron Y., Height growth of jack pine (Pinus banksiana) in relation to site types in boreal forests of Abatibi, Quebec, Can. J. For. Res. 26 (1996) 2170-2179.

[5] Cañadas N., Pinus pinea L. en el Sistema Central (Valles del Tiétar y del Alberche): desarrollo de un modelo de crecimiento y producción de piña, Tesis doctoral, E.T.S.I. de Montes, Universidad Politécnica de Madrid, 2000, 356.

[6] Cao Q.V., Estimating coefficients of base-age invariant site index equations, Can. J. For. Res. 23 (1993) 2343-2347.

[7] Carmean W.H., Site index curves for upland oaks in the Central States, For. Sci. 18 (1972) 109-120.

[8] Carmean W.H., Forest site quality evaluation in the United States, Adv. Agron. 27 (1975) 209-269.

[9] Chen H.Y.H., Klinka K., Kabzems R.D., Height growth and site index models for trembling aspen (Populus tremuloides Michx.) in northern British Columbia, For. Ecol. Manage. 102 (1998) 157-165.

[10] Cieszewski C.J., Bella I.E., Polymorphic height and site index curves for lodgepole pine in Alberta, Can. J. For. Res. 19 (1989) $1151-1160$.

[11] Duplat P., Tran-Ha M., Modélisation de la croissance en hauteur dominante du chêne sessile (Quercus petraea Liebl) en France. Variabilité inter-regionale et effet de la période récente (19591992), Ann. Sci. For. 54 (1997) 611-634.

[12] Eflving B., Kiviste A., Construction of site index equations for Pinus sylvestris L. using permanent plot data in Sweden, For. Ecol. Manage. 98 (1997) 125-134.

[13] Gallant A.R., The power of the likelihood ratio test of location in nonlinear regression models, J. Am. Stat. Assoc. 70 (1975) 198-203.

[14] García Güemes C., Modelo de simulación selvícola para Pinus pinea L. en la provincia de Valladolid, Tesis doctoral, E.T.S.I. de Montes, Universidad Politécnica de Madrid, 1999, 221.

[15] García O., A stochastic differential equation model for the height growth of forest stands, Biometrics 39 (1983) 1059-1072.

[16] Goelz J.C.G., Burk T.E., Development of a well-behaved site index equation: jack pine in north central Ontario, Can. J. For. Res. 22 (1992) 776-784.
[17] Huang S., Development of compatible height and site index models for young and mature stands within an ecosystem-based management framework, in: Amaro A., Tomé M. (Eds.), Empirical and process based models for forest tree and stand growth simulation, 1997.

[18] Huang S., Price D., Titus S.J., Development of ecoregion-based height-diameter models for white spruce in boreal forests, For. Ecol. Manage. 129 (2000) 125-141.

[19] Huet S., Jolivet E., Messéan A., La régression non-linaire : méthodes et applications en biologie, INRA, Paris, 1992.

[20] Johansson T., Site index curves for european aspen (Populus tremula L.) growing on forest land of different soils in Sweden, Silva Fenn. 30 (1996) 437-458.

[21] Khattree R., Naik D.N., Applied multivariate statistics with SAS software, SAS Institute Inc., Cary, NC, 1995.

[22] Kiviste A., Álvarez J.G., Rojo A., Ruiz A.D., Funciones de crecimiento de aplicación en el ámbito forestal, Monografías INIA: Forestal, 4, INIA, Madrid, 2002.

[23] Korf V., A mathematical definition of stand volume growth law, Lesnicka Prace 18 (1939) 337-379.

[24] Monserud R.A., Height-growth and site index curves for inland Douglas fir based on stem analysis and forest habitat type, For. Sci. 30 (1984) 943-965.

[25] Pillsbury N.H., Mc Donald P.M., Reliability of tanoak volume equations when applied to different areas, West. J. App. For. 10 (1995) 72-78.

[26] Pita P.A., Clasificación provisional de las calidades de estación en las masas de pino piñonero, Anales del Instituto Forestal de Investigaciones y Experiencias (1966) 172-182.

[27] Richards F.J., A flexible growth function for empirical use, J. Exp. Bot. 10 (1959) 290-300.

[28] Schumacher F.X., A new growth curve and its application to timber-yield studies, J. For. 37 (1939) 819-820.

[29] Seber G.A.F., Wild C.J., Nonlinear regression, John Wiley \& Sons, New York, 1989.

[30] Weise W., Ertragstafeln für Kiefer, J. Springer, 1880.

[31] Zeide B., Standardization of growth curves, J. For. 76 (1978) 289-292.

[32] Zeide B., Analysis of growth equations, For. Sci. 39 (1993) 594-616

To access this journal online:

www.edpsciences.org 